\title{
Social Networks In The Classroom: Personality Factors As Antecedents Of Student Social Capital
}

\author{
Matthew T. Seevers, Creighton University, USA \\ Bryan R. Johnson, Creighton University, USA \\ Todd C. Darnold, Creighton University, USA
}

\begin{abstract}
This study examines personality factors as antecedents of student social capital. We hypothesize relationships between two constructs taken from the five-factor model of personality (agreeableness and extraversion) and two variables that reflect a student's social capital (quantity of ties and strength of ties) in an academic setting. Analysis of roster-based, sociometric data suggests that agreeableness is associated with higher quantity of ties, but not higher tie strength. In contrast, extraversion is linked to higher tie strength, but not higher overall network size. The paper concludes with a discussion of the implications of student social capital for educational research and practice.
\end{abstract}

Keywords: Personality Factors; Social Networks; Social Capital

\section{INTRODUCTION}

\begin{abstract}
(n recent years, the business education literature - and particularly the marketing education literaturehas witnessed a significant rise in scholarship concerning students' social networks and networking behavior. This interest is fueled by a concern for facilitating student-to-student communication and mutual support (Boostrom, Kurthakoti, and Summey 2009), encouraging networking as a tool to aid students in their professional transition (Bacile 2013; Bevelander and Page 2011; Buff and O'Connor 2012), developing networking skills for the sake of self-marketing and personal branding (McCorkle and McCorkle 2012), and the use of computer-mediated social networks to enhance instruction (Tuten and Marks 2012). This expanding interest is also consistent with the more general growth of research in the business literature that examines the positive benefits of social networks that have been shown to accrue to individuals, groups, and organizations.
\end{abstract}

Although the vast majority of networks research concerns outcomes that are argued to result from network size and structure, scholars have increasingly explored personality variables that, due to their predispositional and enduring nature, are argued to lead to variation in network characteristics. Indeed, personality has been linked to accurate detection of relationships among others (Casciaro 1998) and obtaining advantageous network positions (e.g., Burt, Jannotta, and Mahoney 1998; Kalish and Robbins 2006; Oh and Kilduff 2008) that enhance an individual's creativity (Zhou et al. 2009) and performance (Mehra, Kilduff, and Brass 2001). The latter outcomes are clearly of interest to educators. Marketing education scholars have empirically tested associations between personality and student performance (Nonis et al. 2005; Westerman and Vanka 2005) and student team effectiveness (Amato and Amato 2005; Hutto, Black, and Frontczak 2011; McInnis-Bowers, Chew, and Bowers 2010). Strong interest in the link between personality variables and classroom outcomes is also reflected in studies of teacher evaluations (Bacon and Novotny 2002; Clayson and Sheffet 2006; Schlee 2005).

The purpose of this study is to examine two personality factors (agreeableness and extraversion) as antecedents of social capital, i.e., the resources that flow through one's social network. This paper makes three specific contributions. First, we present and integrate two independent lines of research that are expected to be 
linked to student outcomes, namely social networks and the five-factor (i.e., Big Five) model of personality. In so doing, we introduce social capital theory - a particular aspect of the social networks paradigm - to the marketing education literature as a lens through which student social networks may be explored. Second, we advance hypotheses that examine how agreeableness and extraversions are likely to manifest themselves in two aspects of social capital - quantity and strength of interpersonal ties held by students. Third, we employ sociometric methods to empirically test our hypotheses against personality and interpersonal network data collected from upper-level university business students.

\section{BACKGROUND}

\section{Big Five Personality Factors}

Contemporary research on personality factors is rooted in efforts to establish a taxonomy of attributes used to describe personality characteristics. The first systematic, empirical approach was led by Cattell (e.g., 1943, 1945), who used factor analysis to determine how various descriptors might coalesce into dimensions of personality. Independent investigations that followed the work of Cattell consistently led to a multidimensional representation of personality as "five superordinate constructs" (Digman 1990, p. 420). Consensus in the field supports portraying personality using the five dimensions that have come to be known as the Big Five (Barrick and Mount 1991; Digman 1990). Personality measures reflecting the factors have been shown to be very stable over time (Soldz and Vaillant 1999). Asendorpf and Wilpers (1998), for example, find that measures capturing the Big Five factors are highly stable as students transition from high school into college, and are not influenced by changes in one's social relationships. Research has also found that the five-factor structure has been established in non-English languages and across a variety of cultures (e.g., Mount and Barrick 1995).

The factors that comprise the Big Five model include extraversion, agreeableness, conscientiousness, neuroticism, and openness to experience. Individuals high on extraversion are gregarious, assertive, and energetic (Barrick and Mount 1991). Whereas extraverts prefer to be with other people and larger groups, introverts are more at ease being by themselves or in smaller groups (Costa and McCrae 1992). Individuals high on agreeableness tend to be sympathetic and attentive to the needs of others, as well as good-natured and cooperative, which leads them to be well-liked by others (Barrick and Mount 1991; Costa and McCrae 1992). Conscientious individuals are typically described as reliable, accountable, hardworking, purposeful, and achievement-oriented (Barrick and Mount 1991). It is perhaps not surprising that conscientiousness in students has been consistently linked to their academic performance (e.g., Poropat 2009). The neuroticism factor concerns the emotional stability of an individual; that is, persons low on neuroticism (i.e., high on emotional stability) tend to be calm, even-tempered, and able to maintain composure in the face of adversity (Costa and McCrae 1992). Finally, the openness to experience factor reflects intellectual curiosity, learning motivation, resourcefulness, and willingness to engage in novel experiences (Costa and McCrae 1992; De Raad and Schowenburg 1996).

\section{Social Networks and Social Capital}

The study of social networks typically examines a set of individuals and the ties that link (or fail to link) them together (Barnes 1954; Mitchell 1969). A distinguishing feature of social network analysis is the emphasis it places on relationships among individuals, and the resources that flow from the structure and ties of an individual's network. Such resources are referred to as an individual's social capital (Foley and Edwards 1999; Nahapiet and Ghoshal 1998). Unlike other forms of capital, social capital is not the exclusive property of an individual; instead, it is embedded within relationships, and its value to an individual may increase or decrease as ties are developed or broken (Coleman 1988). Specific examples of social capital-based resources include access to information, such as career advice (Burt 1992; Granovetter 1973); positive word-of-mouth referral from peers (e.g., Seevers, Skinner, and Dahlstrom 2010; Uzzi 1997); and influence in dealing with others (e.g., Seibert, Kraimer, and Liden 2001).

The chief premise of social capital theory is that the resources that flow from one's network may be leveraged to achieve desirable outcomes that may not arise in the absence of these resources. One driver of these resources is a large network that permits a person to reach a variety of interpersonal contacts who possess diverse resources. Burt (1992) argues that it is beneficial for individuals to hold ties to persons who are themselves 
disconnected. Holding numerous ties to persons in different social circles (i.e., spanning "structural holes") limits one's dependence on a small number of contacts who are likely to possess similar resources. The "strength of ties" perspective offered by Granovetter (1973) offers a similar conclusion: holding many so-called weak tiescharacterized as relationships between casual acquaintances who interact infrequently and with limited emotional attachment (Brass, Butterfield, and Skaggs 1998) — enable a person to locate valuable resources (e.g., timely information and novel advice). A second key driver of social capital, however, is an individual's ability to selectively cultivate strong ties. Strong ties permit a person to gain access to valuable resources, and are reflected by higher levels of emotional closeness, trust, and reciprocity (Rindfleisch and Moorman 2001). Indeed, empirical research has established that an individual's social capital - as reflected by reaching out to numerous contacts and gaining trusted access to valuable resources - is positively linked to many beneficial outcomes, including career advancement (e.g., Seibert et al. 2001) and job performance (e.g., Seevers et al. 2010).

\section{Personality Factors, Social Networks, and Education}

Personality theory assumes that an individual's behavior may be explained in part by personality characteristics (Allport 1962). To the degree that personality constructs reflected in the five-factor model are stable (trait) characteristics, they should serve as antecedents to an individual's exposure to social relationships, as well as their development and management of those ties (Asendorpf and Wilpers 1998; Kalish and Robins 2006). An increasing number of studies support this assertion for two of the five personality traits: extraversion and agreeableness. These traits have been shown to account for variation in an individual's network position (e.g., Mehra et al. 2001; Oh and Kilduff 2008; Sasovova et al. 2010) and social network perception (Casciaro 1998). Not only have these two traits been linked to relational behavior, but the language used by scholars to describe them explicitly relies on the language of social relationships. The extraversion factor, for example, is based in part on a person's preference to be sociable and to spend time with others (Costa and McCrae 1992). Similarly, the agreeableness factor hinges on an individual's sensitivity to the needs of others, which engenders liking from those with whom they come into contact (Barrick and Mount 1991).

Studies in the marketing education literature investigating the role of personality have largely been explored independently of studies investigating social networks, but there are benefits to a line of inquiry that examines their linkage. Whereas student characteristics (e.g., IQ, personality, motivation) are uniquely attributable to each student, the characteristics of relationships are shared between and among students. At a macro level, a network perspective offers fertile ground to understand interpersonal connectedness (Granovetter 1985) and social dynamics (e.g., Krishen 2013; Young 2005) that result when students of differing personalities are placed in the same course or work group. At a micro level, consideration of networks - particularly through the lens of social capital theory - sheds light on factors that may mediate the relationship between personality factors and individual student outcomes. Indeed, educators espouse the benefits available to students who are "resourceful," "work well with others," and "partner" with peers to better comprehend course material. Hence, the approach to relationships provided by a networks perspective is well-suited to complement business education research.

\section{HYPOTHESES}

We now build on relevant literature to develop a series of hypotheses that examine anticipated links between personality factors and student social capital. Specifically, we posit that two personality factors (agreeableness and extraversion) are associated with two key variables that reflect a student's social capital: quantity of ties and strength of ties. We also briefly address the remaining three personality factors from the Big Five model (conscientiousness, neuroticism, and openness to experience), which we do not expect to be related to quantity or strength of ties. Figure 1 illustrates our proposed model. 


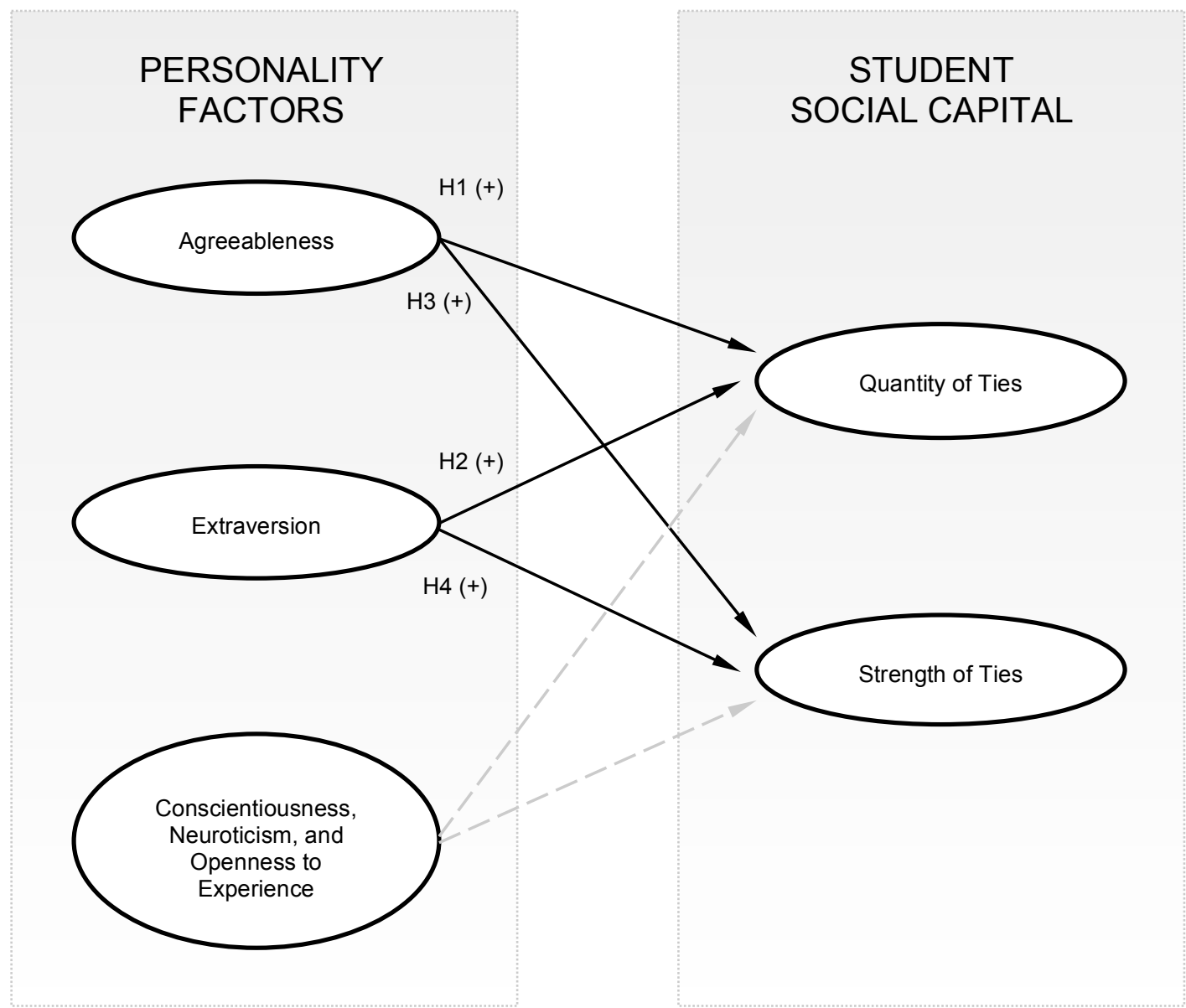

Figure 1. A Model of Personality Factors as Antecedents of Student Social Capital

\section{Agreeableness, Extraversion, and Quantity of Ties}

The quantity of ties held by an individual has been positively linked to many advantages (e.g., Freeman 1979). Persons with numerous ties are able to reach a variety of otherwise unrelated social cliques (Brown and Reingen 1987), thus offering exposure to new opportunities (Burt 1992) and contacts that hold unique resources and perspectives (Lin and Dumin 1986; Seibert et al. 2001). Holding numerous ties also increases personal prominence, which begets cooperation and perceptions of influence (Seevers et al. 2010). We expect these same benefits to extend to academic settings. A student with a large quantity of ties has numerous peers with which to corroborate their understanding of course expectations, materials, and assignments. An extensive network of ties should also ease the process of securing study partners and working with others. Quantity of ties is also positively associated with receipt of emotional support from peers (Lakon, Hipp, and Timberlake 2010), which should aid students in coping with academic stress.

The agreeableness construct reflects an individual's likability. Agreeableness stems from a variety of qualities that are attractive to prospective ties, such as "being courteous, flexible, trusting, good-natured, cooperative, forgiving, soft-hearted, and tolerant" (Barrick and Mount 1991, p. 4). Whereas persons high in agreeableness exhibit endearing interpersonal tendencies, disagreeable individuals tend to display egocentric behaviors and are wary of others' intentions (Costa and McCrae 1992). Xia et al. (2009) suggest agreeable persons are polite and easy to talk to, which makes them desirable targets of relational efforts. In an educational context, the agreeableness factor has been linked to compliance with teacher instructions (Vermetten, Lodewijks, and Vermunt 2001) and academic performance (Poropat 2009). This suggests that an agreeable student may be a good source of course-related information. Taken as a whole, prior research suggests that students high on agreeableness are 
attractive to peers as potential friends or acquaintances. In turn, when agreeable individuals initiate relationships with peers, their efforts are likely to be well-received. Thus, we expect the following:

H1: Agreeableness will be positively related to quantity of ties.

A hallmark of the extraversion construct is an individual's preference and ability to engage with others in social interaction. Extraverts like people and enjoy the company of others (Costa and McCrae 1992). It is perhaps not surprising then that extraversion is a strong predictor of entering the sales profession (Barrick and Mount 1991) and performing well in a sales role (Stevens and Macintosh 2003). Extraversion has also been described using terms that relate to ambition, such as initiative, assertiveness, and energy (Hogan 1986). This suggests that extraverts not only have a preference to hold relationships, but also the volition to act on relational impulses. In a longitudinal study of college freshman, Asendorpf and Wilpers (1998) found that extraverted students (as compared to students reporting to be more shy) developed more ties to their peers and grew their network at a faster rate. Using a student sample, Kalish and Robbins (2006) find that respondents high (versus low) on extraversion report a larger number of ties in their personal network. This evidence leads us to expect a positive association between extraversion and quantity of ties. Formally, we hypothesize:

H2: Extraversion will be positively related to quantity of ties.

\section{Agreeableness, Extraversion, and Strength of Ties}

Tie strength is among the most studied relational features in the social network paradigm. Granovetter (1973, p. 1361) describes tie strength as a "combination of the amount of time, the emotional intensity, the intimacy (mutual confiding), and the reciprocal services" that characterizes a relationship. Strong ties are exemplified by high levels of trust and cooperation (Rindfleisch and Moorman 2001) that contribute to lower interpersonal conflict (Nelson 1989). These qualities enhance communication. Tie strength has been positively linked to the amount (Rindfleisch and Moorman 2001) and quality (Frenzen and Nakamoto 1993; Hansen 1999; Uzzi 1997) of information transfer. Furthermore, information conveyed in a strong tie relationship carries more weight in the receiver's decision-making (Brown and Reingen 1987). In academic settings, we expect strong tie peers to be more willing to discuss course-related matters and to provide assistance, such as sharing notes. Close relationships may also be particularly beneficial to a student's performance related to activities that require cooperation and coordination.

Agreeable persons are distinguished by their likability and attractiveness to prospective ties. The same qualities that evince positive initial impressions about an individual may also serve to draw others closer. Indeed, Barrick and Mount (1991) characterize agreeableness using terms - trusting, cooperative, forgiving, tolerant - that parallel descriptions of strong ties. Costa and McCrae (1992) suggest that persons high in agreeableness are eager to help others and believe that others will return the favor. We, therefore, anticipate that students that measure high (versus low) on agreeableness are more likely to hold ties that are closer on average. Prior empirical research on this matter is limited. Asendorpf and Wilpers (1998) did not report an association between agreeableness and relationship duration. They did, however, find agreeableness is linked to lower levels of conflict with peers, which is consistent with the strength of ties literature (Nelson 1989). Thus, we expect:

H3: Agreeableness will be positively related to strength of ties.

Extraversion is exemplified by an affinity for and motivation to pursue social interaction (Costa and McCrae 1992). Extraverts have also been described as energetic and assertive (Hogan 1986), both of which are qualities that are likely to fuel a willingness to invest time and effort necessary to cultivate strong relationships. Supporting this logic, Kalish and Robbins (2006) report that individuals scoring high on extraversion tend toward personal networks that are rich in overlapping ties - a pattern that reflects increased tie strength. Extraverted (versus introverted) students also have increased interaction and receive more support from peers, and are more likely to report high levels of relationship intimacy (Asendorpf and Wilpers 1998). Thus, we expect that extraversion will be linked to the average strength of one's relationships. 
H4: Extraversion will be positively related to strength of ties.

\section{Conscientiousness, Neuroticism, and Openness to Experience}

Based on a review of the personality factor literature, we do not expect tie quantity or tie strength to be related to any of the three remaining Big Five factors: conscientiousness, neuroticism, or openness to experience. Kalish and Robbins (2006) failed to find support for a negative association between neuroticism and quantity of ties. Asendorpf and Wilpers (1998) did not find evidence that any of these three factors influenced peer network size. Interestingly, these same authors reported a linkage between conscientiousness and tie strength (as indicated by contact frequency), but only with family members, and not with fellow students. To provide a stronger test of the preceding hypotheses, we included conscientiousness, neuroticism, and openness to experience as control variables in our analysis, which is described in the section that follows.

\section{METHOD}

\section{Sample}

Data for this study were drawn from 52 undergraduate students participating in a popular business course at a private, midwestern university. ${ }^{1}$ Among students taking the course, the most common major was marketing. All students enrolled in the course were included in the study to allow all possible relationships among participants in the sample to be identified and recorded. The data were collected by the course instructor, who administered a paper-and-pencil survey during class time. Students were informed that the aggregated (and anonymous) results would be used for discussion in a future class period, which increased students' involvement and interest in the study. The average age of participants in the sample was 21.3 years, with most of the students enrolled as juniors. The sample consisted of 20 females (38\%) and 32 males (62\%). The average number of credit hours completed by study participants was 82 hours, with an average student GPA of 3.45. We obtained a variety of social network and personality data for participants, as depicted in Table 1 and in the following section.

Table 1. Means, Standard Deviations, and Correlations

\begin{tabular}{|c|c|c|c|c|c|c|c|c|c|c|c|c|c|}
\hline & Variable & Mean & S.D. & Min & Max & 1 & 2 & 3 & 4 & 5 & 6 & 7 & 8 \\
\hline 1 & Quantity of Ties & 15.23 & 5.74 & 3 & 29 & & & & & & & & \\
\hline 2 & Strength of Ties & 1.67 & 0.24 & 1.2 & 2.2 & -.02 & & & & & & & \\
\hline 3 & Agreeableness & 39.04 & 5.68 & 21 & 49 & $.39 * *$ & .04 & & & & & & \\
\hline 4 & Extraversion & 34.61 & 5.98 & 21 & 46 & .24 & .26 & .17 & & & & & \\
\hline 5 & Conscientiousness & 37.87 & 5.52 & 25 & 50 & .00 & .11 & .23 & .00 & & & & \\
\hline 6 & Neuroticism & 33.06 & 6.29 & 20 & 48 & .08 & .22 & .22 & -.09 & -.05 & & & \\
\hline 7 & Openness to Experience & 36.19 & 4.82 & 26 & 44 & .26 & -.01 & .03 & $.34 *$ & -.04 & .12 & & \\
\hline 8 & Gender & 0.62 & & 0 & 1 & .05 & .11 & -.16 & .06 & -.01 & .05 & $.31^{*}$ & \\
\hline 9 & Social Desirability & 3.19 & 2.04 & 0 & 7 & .18 & .21 & $.34 *$ & -.21 & .14 & $.41 * *$ & -.02 & .08 \\
\hline
\end{tabular}

\section{Dependent Variables}

The network measures that reflected student social capital were collected using sociometric questions in which participants reported relationships with fellow students. Respondents were provided an alphabetical roster of all students enrolled in the course and were asked to indicate ties to individuals with whom they had interacted. The survey was conducted near the end of the semester (approximately three months from the start of the course). We followed established network research protocols to enhance the accuracy of the network ties identified by participants. As recommended in previous network studies: (1) we provided respondents with a complete list of

\footnotetext{
${ }^{1}$ The unique challenges of collecting relational data from all participants in a network often lead to smaller sample sizes than those that result from other forms of research. Network studies of this type require documenting the nature of each participant's unique relationship with every other participant. A key benefit is that responses from each party to a relationship may be verified against the other party to account for accuracy and reliability of the data. In the current study, identifying the relationships among participants required assessment of 1326 possible unique dyads among the 52 students. As sample sizes increase, the number of possible unique dyads increases exponentially. For these reasons, network studies involving primary sociometric data collection are often characterized by smaller samples, typically involving fewer than 40 participants (e.g., Kilduff and Krackhardt 1994; Krackhardt and Kilduff 1990; Krackhardt and Porter 1986; Krackhardt 1990).
} 
participants to facilitate recall, (2) we provided participants with cues to define the types of relationships relevant to the current inquiry, and (3) we inquired about long-term, stable relationships that can accurately be recalled by participants (Freeman, Romney, and Freeman 1987; Knoke and Kuklinski 1982; Wasserman and Faust 1994). The 52 students shared 396 ties to one another, which represented $29.9 \%$ of $1326(\mathrm{n} * \mathrm{n}-1 / 2)$ possible student-to-student dyads. Figure 2 provides visual representation of the social network examined in this study, incorporating the students and the ties among them.

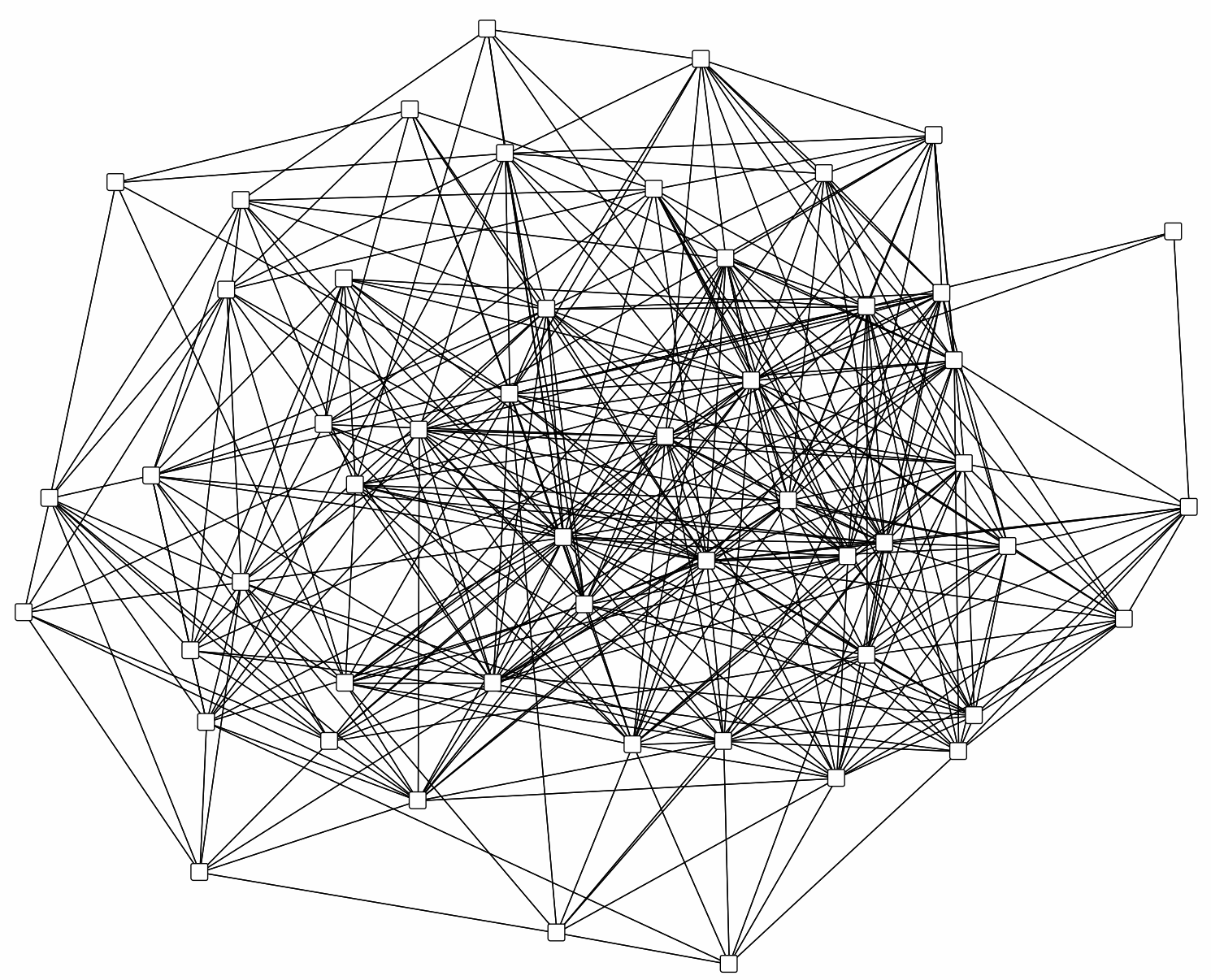

This sociogram illustrates the complete social network among all student participants $(n=52)$ in the study. The boxes (nodes) depict individual students and the lines represent relationships between students. The sociogram is produced using Netdraw's (Borgatti et al. 2002) node repulsion and equal edge length algorithm, which places students with more shared ties closer to one another and students with fewer shared ties farther from one another. In addition, relationships between students are represented at equal distances to improve visualization of all students in the network, collectively.

Figure 2. Sociogram of Student Social Network

Quantity of ties was measured using degree centrality, which is a count of the number of unique relationships each actor has with others in the network (Freeman 1979). Strength of ties was created by taking the mean of respondents' ratings of the emotional closeness of their ties with others, using a 3-point scale in which $1=$ acquaintance, $2=$ friend, and 3=close friend (Burt 1992; Marsden and Campbell 1984). ${ }^{2}$

\footnotetext{
${ }^{2}$ Respondents only rated tie strength for a relationship once they reported that a relationship existed. Students were instructed to leave all questions blank for individuals with whom they had no relationship. We averaged strength ratings to create the variable strength of ties. Raw network responses were transformed using the "Symmetrize Maximum" function in UCINET (Borgatti et al. 2002), which sets the strength for each dyad to the maximum level reported by either member of the dyad.
} 


\section{Independent Variables}

The two personality factors were measured with multi-item scales drawn from the established Big Five personality inventory (Digman 1990; Goldberg 1990). Specifically, the items were taken from the 50-item International Personality Item Pool (IPIP) (Goldberg 1992). Each item is measured with a 5-point scale ranging from $1=$ very inaccurate to $5=$ very accurate. Extraversion $(\alpha=.79)$ was captured with 10 items, including "talk to a lot of people at parties," "start conversations," and "feel comfortable around people." Agreeableness $(\alpha=.84)$ was captured with 10 items, such as "make people feel at ease," "take time out for others," and "am interested in people."

\section{Control Variables}

In addition to the focal personality factors of interest, we also included the remaining three dimensions of the Big Five personality inventory to account for their association with student social capital. Each dimension was captured with 10-items from the IPIP (Goldberg 1992). The reliability of each scale was found to be acceptable: conscientiousness $(\alpha=.76)$, neuroticism $(\alpha=.80)$, and openness to experience $(\alpha=.76)$. Gender $(\mathrm{female}=0$, male $=1)$ is included to account for any possible differences between males and females. We included an 8-item measure of social desirability bias $(\alpha=.64)$ based on Crowne and Marlowe's (1960) scale to control for any socially desirable responding by participants.

\section{ANALYSIS AND RESULTS}

To assess the influence of individual personality factors on the development of student social capital, we estimated regression models with the Big Five personality factors, gender, and social desirability bias as explanatory variables, and the student social capital measures (quantity of ties and strength of ties) as individual response variables (see Table 2, Models 1 and 2).

Model 1 demonstrates the impact of personality on the quantity of ties participants formed with other students. As posited in $\mathrm{H}_{1}$, the analysis demonstrates that agreeableness $(\beta=0.36 ; p<.05)$ has a statistically significant relationship with the size of students' networks in our sample. However, extraversion $(\beta=0.13 ; p>.05)$ was not found to have a significant relationship with student network size, as posted in $\mathrm{H}_{2}$.

Model 2 captures the effects of personality factors on the strength of ties participants developed with peers. We find that extraversion $(\beta=0.41 ; p<.01)$ has a significant relationship with a student's average tie strength in their network. This result lends strong support to $\mathrm{H}_{4}$. Alternatively, we find that agreeableness is not associated with average tie strength $(\beta=-0.17 ; p>.05)$; hence, we do not find support for $\mathrm{H}_{3}$.

Adding confidence to the findings, support of $\mathrm{H}_{1}$ and $\mathrm{H}_{4}$ were found while accounting for the influence of the control variables included in the regression models. Neither model supported a significant association between any of the three remaining personality factors (conscientiousness, neuroticism, or openness to experience) and either quantity of ties or strength of ties. Furthermore, the results show that gender and social desirability bias were not associated with either measure of student social capital. 
Table 2. Regression Results: Personality Factors and Student Social Capital

\begin{tabular}{lcc}
\hline & $\begin{array}{c}\text { Model 1 } \\
\text { Quantity of Ties (Degree) }\end{array}$ & $\begin{array}{c}\text { Model 2 } \\
\text { Strength of Ties (Average) }\end{array}$ \\
\hline Independent Variables & & -0.17 \\
\hline Agreeableness & $0.36^{*}$ & $(0.01)$ \\
& $(0.15)$ & $0.41^{* *}$ \\
Extraversion & 0.13 & $(0.01)$ \\
\hline Control Variables & $(0.14)$ & 0.13 \\
\hline Conscientiousness & & $(0.01)$ \\
Neuroticism & -0.10 & 0.22 \\
& $(0.14)$ & $(0.01)$ \\
Openness to Experience & -0.08 & -0.19 \\
Gender & $(0.13)$ & $(0.01)$ \\
Social Desirability Bias & 0.20 & 0.10 \\
& $(0.18)$ & $(0.07)$ \\
\hline Model Statistics & 0.02 & 0.23 \\
$\mathrm{R}^{2}$ & $(1.67)$ & $(0.02)$ \\
\hline $\mathrm{N}$ & 0.14 & 0.22 \\
\hline
\end{tabular}

All beta coefficients reported are standardized.

Standard errors are displayed in parentheses below coefficients.

Significance is based on 2-tailed tests: $* \mathrm{p} \leq 0.05 ; * * \mathrm{p} \leq 0.01$.

\section{DISCUSSION}

The purpose of this study has been to investigate whether and how personality factors serve as antecedents of student social capital in an academic setting. Specifically, we posited relationships between two personality constructs taken from the five-factor model (agreeableness and extraversion) and two variables that reflect a student's social capital (quantity of ties and strength of ties). The results suggest that agreeableness is associated with higher quantity of ties, but not higher tie strength. In contrast, we find that extraversion is linked to higher tie strength, but not higher overall network size. The results suggest that two different personality factors play unique roles in helping students develop their social capital in academic settings.

\section{Implications for Researchers}

This study offers a number of contributions to the literature in marketing education, as well as to the broader business education literature. First, we have offered logic to support a joint consideration of two independent lines of research-social networks and the five-factor model of personality-that are of interest to business educators. Second, we have introduced social capital theory to the literature, which may shed light on how social networks mediate the relationship between personality factors and student outcomes. Indeed, we encourage future research that explores a causal flow from personality factors to social networks to academic performance. Future research might also examine how personality factors may contribute to group-level social capital that aids (or perhaps impedes) team performance. Third, we have employed established sociometric methods that give increased confidence in our measurement of student social capital. Social network analysis offers a fertile set of tools that may be used to capture the many relational aspects of academic environments that are inherently shared between and among students and instructors.

The results of the current study extend our understanding of how specific personality factors are related to student social capital. Agreeableness has been positively linked to compliance with teacher instructions (Vermetten, Lodewijks, and Vermunt 2001) and academic performance (Poropat 2009). Although prior research is suggestive of a link between agreeableness and the size of a student's network, no prior empirical work has established this association. The current study is among the first to find a positive relationship between agreeableness and network size. In terms of tie strength, the current results mirror the limited research that investigates agreeableness and tie 
strength. In their empirical study, Asendorpf and Wilpers (1998) did not find a relationship between agreeableness and an indicator of tie strength, relationship duration. Consistent with the findings of these authors, we also did not find a linkage between agreeableness and the average strength of a student's ties. Whereas agreeableness appears to be useful to students for holding many ties, the results do not show that this personality factor is associated with holding deep, meaningful relationships across one's network.

The current results also enhance our understanding of the role of extraversion in the development of one's social capital in an academic setting. Prior research finds that extraverted individuals are more likely to hold networks rich in overlapping ties (Kalish and Robbins 2006). Asendorpf and Wilpers (1998) report a positive linkage between extraversion and interaction with and social support from peers. Indeed, the current study is consistent with these findings - we find that extraversion is strongly and positively associated with average tie strength. Put differently, our results affirm prior research that suggests that the initiative, assertiveness, and energy typical of extraverts is valuable for the cultivation of deep, meaningful ties. Perhaps the most surprising result from the current study is that extraversion was not linked to quantity of ties, which counters the findings of Asendorpf and Wilpers (1998) and Kalish and Robbins (2006). We speculate that this difference may be due to our intensive efforts to verify the existence of relationships from both persons in all respondent pairs. By contrast, the earlier studies rely solely on self-reports. This suggests that it may be fruitful to investigate an association between personality factors, such as extraversion, and a proneness to over-report the existence of reciprocated social network ties.

We point out two limitations to the current study. First, although cross-sectional data restricts causal inference, the extent to which personality factors are stable (trait) over time provides confidence that personality precedes networking behavior. In accordance with established network research protocols, our focus on longer-term relationships (Freeman et al. 1987) also counteracts the weakness of cross-sectional data. Second, while the sample size for the current study is larger than many studies in social networks research (cf. Kilduff and Krackhardt 1994; Krackhardt and Kilduff 1990; Krackhardt and Porter 1986; Krackhardt 1990), it is modest relative to other types of survey research. We, therefore, encourage readers to use caution when interpreting the results and applying them to different academic contexts. Additional research is needed to better understand how the linkage between personality factors and student social capital may be affected by network size, whether larger or smaller. This is especially true given that increasingly large networks may place an upper limit on the number of ties developed by any one member of the network (Scott 2000).

\section{Implications for Educators}

The results of this study illuminate a new way for educators to conceptualize and understand the impact of personality factors on interaction among students. Before discussing application for educators, we first acknowledge a practical challenge to utilizing the findings - namely, instructors must have a mechanism to assess students' personality factors. A primary option available to instructors is to administer the 50-item International Personality Item Pool (IPIP) (Goldberg 1992) that was used in this study. The items themselves are short and the entire scale generally requires no more than 5-10 minutes to complete. Alternative versions of the scale are also widely available, including shorter assessments of the five-factor model, such as those advanced by Saucier (e.g., 1994). For instructors with many students, we highly recommend using a web-based survey tool to collect this data. Conversely, instructors with fewer students might also intuitively estimate personality factors based on their firsthand interactions with students.

One important implication of our research involves the assignment of students to groups, based on student personality types. Prior research in marketing education suggests that matching students based on the results of personality indicators is likely to influence the group's experience and performance (e.g., Amato and Amato 2005; Hutto et al. 2011). Behind this prescription is the notion that teams benefit from diversity in cognitive styles (e.g., Culp and Smith 2001). The current findings suggest that personality factors may serve as an effective proxy for social dynamics among potential team members.

When assigning students to groups, the importance of personality factors may be particularly heightened when in-group closeness or out-group reach are central to a collaborative project. For example, the performance of a team comprised of only introverted students may suffer if close, working relationships (i.e., strength of ties) are 
critical to group tasks. Alternatively, strategically placing extraverted students into groups may help to enhance group interactions and performance. Similarly, proactively assigning group membership based on personality factors may help in contexts in which ties to many other individuals (i.e., quantity of ties) are advantageous. Consider a group task that requires team members to reach out to build a variety of ties to persons outside of the group. In this situation, a group comprised of students with low levels of agreeableness may be disadvantaged because their existing networks may be relatively small, whereas those with high levels of agreeableness would be expected to be able to establish and leverage external ties in order to benefit the group.

Another important implication of our research is the potential benefit that managing personality factors offers in the domain of student advising and counseling. At times, certain students, who-due to predispositional and enduring personality factors - may find it difficult to initiate, develop, and maintain key relationships with peers. Specifically, the results of our study suggest that students who exhibit low levels of extraversion and agreeableness may be challenged to build social capital with their peers, which may be an impediment to their academic experience and performance. Further, we speculate that these students may also be hampered in the development of other vital relationships that are affiliated with academic success, such as those to faculty, academic support staff, academic counselors and advisors, and even prospective employers. Such pre-professional networking is critical for students, as it has been shown to impact numerous aspects of students' academic and long term goals, such as finding internships and jobs (e.g., Granovetter 1973), enhancing career outcomes (Gabbay and Zuckerman 1998), increasing earnings (Boxman, De Graaf, and Hendrik, 1991), and creating opportunities for mentoring and promotions (e.g., Seibert et al. 2001). Therefore, in counseling or advising settings, we encourage educators to consider personality traits as they assist students with the development of interpersonal skills and networking abilities, in order to enhance students' comfort with important networking activities.

The current study highlights the value of student social capital, and how personality factors are likely to contribute to its development over time. We take this opportunity to suggest additional pedagogical techniques that may facilitate social support among students. In particular, we encourage the use of classroom interventions that promote interaction among students. Prior research suggests that physical proximity between individuals contributes to interaction (e.g., Rice and Aydin 1991); hence, without instructor intervention, pairs of students who are physically distant (versus physically proximate) are less likely to become acquainted. To remedy this situation, instructors might regularly hold breakout discussions during class time and pair (or group) students who do not typically sit near one another (see also Gonzalez et al. 2004). This type of activity may help students break the ice with more peers and contribute to increasing the size of students' networks. Another alternative is to assign teambuilding exercises that enhance students' sense of familiarity and trust with the peers. Such activities serve to strengthen ties within a team and may foster higher levels of cooperation.

\section{CONCLUSION}

Our results suggest that business educators in possession of information about students' personality traits put themselves in a position to better understand the social context in which their student operate. Assessing and managing student personality factors allows educators to appreciate and cultivate the way students interact with others. Understanding student personality traits also provides educators with the opportunity to help students better understand how others perceive their interactions and behaviors, and how personality factors impact their success as individuals and in group settings. It is our hope that findings resulting from this study will not only help educators to improve students' educational experiences, but also to prepare students for sustained academic success and positive career outcomes.

\section{AUTHOR INFORMATION}

Matt Seevers, Ph.D. (University of Kentucky), is Chair of the Department of Marketing \& Management and serves as Associate Professor of Marketing in the Heider College of Business at Creighton University. His research often centers on the implications of social capital that derives from interpersonal relationships in the marketplace. His work appears in a variety of journals, including the Journal of Retailing, Journal of Personal Selling \& Sales Management, Marketing Management Journal, Journal of Travel Research, and Marketing Education Review. Email: matt.seevers@creighton.edu 
Bryan R. Johnson, Ph.D. (Pennsylvania State University), is Assistant Professor of Marketing in the Heider College of Business at Creighton University, where he teaches courses in consumer behavior and advertising. His research in the marketing field typically involves social phenomena, such as social relationships, social capital, and social networks. His current work focuses on understanding the marketing and social implications of commercial friendships that develop between firm representatives and consumers. Email: bryan@creighton.edu

Todd Darnold, Ph.D. (University of Iowa), is Associate Professor of Management in the Heider College of Business at Creighton University. He serves as the MBA Program Director, as well as Director of Creighton's Anna Tyler Waite Leadership Program. Todd teaches courses in the areas of organizational behavior, human resources, and leadership. His academic work has been published in outlets such as The Journal of Applied Psychology, Personnel Review, Leadership Quarterly, and The Oxford Handbook of Recruitment. Email: todddarnold@creighton.edu

\section{REFERENCES}

Allport, G.W. (1962). The general and the unique in psychological science. Journal of Personality, 30(3), 405-422. Amato, C.H., \& Amato, L.H. (2005). Enhancing student team effectiveness: application of myers-briggs personality assessment in business courses. Journal of Marketing Education, 27(April), 41-51.

Asendorpf, J.B., \& Wilpers, S. (1998). Personality effects on social relationships. Journal of Personality and Social Psychology, 74(6), 1531-1544.

Bacile, T.J. (2013). The klout challenge: preparing your students for social media marketing. Marketing Education Review, 23(Spring), 87-92.

Bacon, D.R., \& Novotny, J. (2002). Exploring achievement striving as a moderator of the grading leniency effect. Journal of Marketing Education, 24(April), 4-14.

Barnes, J. (1954). Class and committees in a norwegian island parish. Human Relations, 7(1), 39-58.

Barrick, M. R., \& Mount, M.K. (1991). The big five personality dimensions and job performance: a meta-analysis. Personnel Psychology, 44(Spring), 1-26.

Bevelander, D., \& Page, J.P. (2011). Ms. trust: gender, networks and trust—implications for management and education. Academy of Management Learning \& Education, 2011(4), 623-642.

Boostrom, R.E., Jr., \& Kurthakoti, R., \& Summey, J.H. (2009). Enhancing class communication through segregated social networks. Marketing Education Review, 19(Spring), 37-41.

Borgatti, S.P., Everett, M.G., \& Freeman, L.C. (2002). Ucinet for Windows: Software for Social Network Analysis, Harvard: Analytic Technologies.

Boxman, E., De Graaf, P.M., \& Flap, H.D. (1991). The impact of social and human capital on the income attainment of dutch managers. Social Networks, 13(1), 51-73.

Brass, D.J., Butterfield, K.D., \& Skaggs, B.C. (1998). Relationships and unethical behavior: a social network perspective. Academy of Management Review, 23(January), 14-31.

Brown, J.J., \& Reingen, P.H. (1987). Social ties and word-of-mouth referral behavior. Journal of Consumer Research, 14(December), 350-362.

Buff, C. L., \& O’Connor, S. (2012). Marketing career speed networking: a classroom event to foster career awareness. Marketing Education Review, 22(Spring), 77-82.

Burt, R.S. (1992). Structural Holes: The Social Structure of Competition. Cambridge, MA: Harvard University Press.

Burt, R.S., Jannotta, J.E., \& Mahoney, J.T. (1998). Personality correlates of structural holes. Social Networks, 20 , 63-87.

Casciaro, T. (1998). Seeing things clearly: social structure, personality, and accuracy in social network perception. Social Networks, 20, 331-51.

Cattell, R.B. (1943). The description of personality: basic traits resolved into clusters. Journal of Abnormal and Social Psychology, 38, 476-506.

Cattell, R.B. (1945). The description of personality: principles and findings in a factor analysis. American Journal of Psychology, 58, 69-90.

Clayson, D.E., \& Sheffet, M.J. (2006). Personality and the student evaluation of teaching. Journal of Marketing Education, 28(August), 149-160.

Coleman, J.S. (1988). Social capital in the creation of human capital. The American Journal of Sociology, 94 (Supplement), S95-S120.

Costa, P.T., \& McCrae, R.R. (1992). Revised NEO Personality Inventory NEO Five-Factor Inventory Professional Manual, Odessa, FL: Psychological Assessment Resources.

Crowne, D.P., \& Marlowe, D. (1960). A new scale of social desirability independent of psychopathology. Journal of 
Consulting Psychology, 24(4), 349.

Culp, G. \& Smith, A. (2001). Understanding psychological type to improve project team performance. Journal of Management in Engineering, 17(1), 24-33.

De Raad, B., \& Schouwenburg, H.C. (1996). Personality in learning and education: a review. European Journal of Personality, 10(5), 303-336.

Digman, J.M. (1990). Personality structure: emergence of the five-factor model. Annual Review of Psychology, 41, 417440.

Foley, M.W., \& Edwards, B. (1999). Is it time to disinvest in social capital? Journal of Public Policy, 19(2), $141-173$.

Freeman, L. (1979). Centrality in social networks: conceptual clarification. Social Networks, 1(February), $215-239$.

Freeman, L., Romney, A.K., \& Freeman, S.C. (1987). Cognitive structure and informant accuracy. American Anthropologist, 89(June), 310-325.

Frenzen, J., \& Nakamoto, K. (1993). Structure, cooperation, and the flow of market information. Journal of Consumer Research, 20(December), 360-375.

Gabbay, S.M. \& Zuckerman, E.W. (1998). The contingent effect of contact density on mobility expectations. Social Science Research, 27, 189-217.

Goldberg, L.R. (1990). An alternative 'description of personality': the big-five factor structure. Journal of Personality and Social Psychology, 59(6), 1216-1229.

Goldberg, L.R. (1992). The development of markers for the big-five factor structure. Psychological Assessment, 4, $26-42$.

Gonzalez, G. R., Ingram, T. N., LaForge, R. W., \& Leigh, T. W. (2004). Social capital: Building an effective learning environment in marketing classes. Marketing Education Review, 14(2), 1-7.

Granovetter, M.S. (1973). The strength of weak ties. American Journal of Sociology, 78, 1360-1380.

Granovetter, M.S. (1985). Economic action and social structure: the problem of embeddedness. American Journal of Sociology, 91(November), 481-510.

Hansen, M.T. (1999). The search-transfer problem: the role of weak ties in sharing knowledge across organization subunits. Administrative Science Quarterly, 44(March), 82-111.

Hutto, A., Black, G.S., \& Frontczak, N.T. (2011). Matchmaking in marketing class: using fisher's personality profiling to form student teams. Marketing Education Review, 21(Spring), 43-48.

Kalish, Y., \& Robbins, G. (2006). Psychological predispositions and network structure: the relationships between individual predispositions, structural holes, and network closure. Social Networks, 28, 56-84.

Kilduff, M., \& Krackhardt, D. (1994). Bringing the individual back in: a structural analysis of the internal market for reputation in organizations. Academy of Management Journal, 37(1), 87-108.

Knoke, D. \& Kuklinski, J.H. (1982). Network Analysis, Beverly Hills, CA: Sage Publications.

Krackhardt, D. (1990). Assessing the political landscape: structure, cognition, and power in organizations. Administrative Science Quarterly, 35, 342-369.

Krackhardt, D. \& Porter, L. (1986). The snowball effect: turnover embedded in communication networks. Journal of Applied Psychology, 71(1), 50-55.

Krackhardt, D. \& Kilduff, M. (1990). Whether close or far: social distance effects on perceived balance in friendship networks. Journal of Personality and Social Psychology, 76 (5), 770-782.

Krishen, A. (2013). Catch it if you can: how contagious motivation improves group projects and course satisfaction. Journal of Marketing Education, 35(December), 220-230.

Lakon, C., Hipp, J.R., \& Timberlake, D.S. (2010). The social context of adolescent smoking: a systems perspective. American Journal of Public Health, 100(7), 1218-1228.

Lin, N., \& Dumin, M. (1986). Access to occupations through social ties. Social Networks, 8, 365-385.

Marsden, P.V., \& Campbell, K.E. (1984). Measuring tie strength. Social Forces, 63(December), $482-501$.

McCorkle, D.E., \& McCorkle, Y.L. (2012). Using linkedin in the marketing classroom: exploratory insights and recommendations for teaching social media/networking. Marketing Education Review, 22(Summer), 157-166.

McInnis-Bowers, C., Chew, E.B., \& Bowers, M.R. (2010). Using reflective thinking to enhance decision skills, cultural sensitivity, and teamwork. Marketing Education Review, 20(Spring), 17-20.

Mehra, A., Kilduff, M., \& Brass, D.J. (2001). The social networks of high and low self-monitors: implications for workplace performance. Administrative Science Quarterly, 46(March), 121-146.

Mitchell, J.C. (1969). The concept and use of social networks. In J.C. Mitchell (Ed.), Social networks in urban situations: analyses of personal relationships in central african towns, Manchester: Manchester University Press.

Mount, M.K., \& Barrick, M.R. (1995). The big five personality dimensions: implications for research and practice in human resources management. Research in Personnel and Human Resources Management, 13(3), 153-200.

Nahapiet, J., \& Ghoshal, S. (1998). Social capital, intellectual capital, and the organizational advantage. Academy of Management Review, 23(April): 242-266.

Nelson, R.E. (1989). The strength of strong ties: social networks and intergroup conflict in organizations. Academy of 
Management Journal, 32(June), 377-401.

Nonis, S.A., Philhours, M., Syamil, A., \& Hudson, G.I. (2005). The impact of non-intellectual variables on the academic success of business students. Marketing Education Review, 15(Fall), 51-63.

Oh, H., \& Kilduff, M. (2008). The ripple effect of personality on social structure: self-monitoring origins of network brokerage. Journal of Applied Psychology, 93(5), 1155-1164.

Poropat, A.E. (2009). A meta-analysis of the five-factor model of personality and academic performance. Psychological Bulletin, 135(2), 322-38.

Rice, R.E. \& Aydin, C. (1991). Attitudes toward new organizational technology: Network proximity as a mechanism for social information processing. Administrative Science Quarterly, 36 (June), 219-244.

Rindfleisch, A., \& Moorman, C. (2001). The acquisition and utilization of information in new product alliances: a strength-of-ties perspective. Journal of Marketing, 65(April): 1-18.

Sasovova, Z., Mehra, A., Borgatti, S.P., \& Schippers, M.C. (2010). Network churn: the effects of self-monitoring personality on brokerage dynamics. Administrative Science Quarterly, 55(December), 639-670.

Saucier, G. (1994). Mini-markers: A brief version of Goldberg's unipolar big-five markers. Journal of Personality Assessment, 63(3), 506-516.

Schlee, R.P. (2005). Social styles of students and professors: do students' social styles influence their preferences for professors? Journal of Marketing Education, 27(August), 130-142.

Scott, J. (2000). Social Network Analysis: A Handbook, London: Sage Publications.

Seevers, M.T., Skinner, S.J., \& Dahlstrom, R. (2010). Performance implications of a retail purchasing network: the role of social capital. Journal of Retailing, 86(December), 356-367.

Seibert, S.E., Kraimer, M.L., \& Liden, R.C. (2001). A social capital theory of career success. Academy of Management Journal, 44(2), 219-237.

Soldz, S., \& Vaillant, G.E. (1999). The big five personality traits and the life course: a 45-year longitudinal study. Journal of Research in Personality, 33(2), 208-232.

Stevens, C.D., \& Macintosh, G. (2003). Personality and attractiveness of activities within sales jobs. Journal of Personal Selling \& Sales Management, 23(Winter), 23-37.

Till, B.D., Zravkovic, S., \& Morrison, B. (2010). M-B indicator and advertising careers. Journal for Advancement of Marketing Education, 17(Winter), 28-38.

Tuten, T., \& Marks, M. (2012). The adoption of social media as educational technology among marketing educators. Marketing Education Review, 22(Fall), 201-214.

Uzzi, B. (1997). Social structure and competition in interfirm networks: the paradox of embeddedness. Administrative Science Quarterly, 42(March), 35-67.

Vermetten, Y.J., Lodewijks, H.G., \& Vermunt, J.D. (2001). The role of personality traits and goal orientations in strategy use. Contemporary Educational Psychology 26(2), 149-170.

Wasserman, S., \& Faust, K. (1994). Social Network Analysis: Methods and Applications. New York: Cambridge University Press.

Westerman, J.W., \& Vanka, S. (2005). A cross-cultural empirical analysis of person-organization fit measures as predictors of student performance in business education: comparing students in the united states and india. Academy of Management Learning \& Education, 4(4), 409-420.

Xia, L.Y., Yuan, C., \& Gay, G. (2009). Exploring negative group dynamics: adversarial network, personality, and performance in project groups. Management Communication Quarterly, 23(August), 32-62.

Young, M.R. (2005). The motivational effects of the classroom environment in facilitating self-regulated learning. Journal of Marketing Education, 27(April), 25-40.

Zhou, J., Shung, J.S., Brass, D.J., Choi, J., \& Zhang, Z. (2009). Social networks, personal values, and creativity: evidence for curvilinear and interaction effects. Journal of Applied Psychology, 94(6), 1544-1552. 